Paper published in:

Punch, S. (2002) 'Research with Children: The Same or Different from Research with Adults?' Childhood, 9 (3): 321-341.

\title{
Research with children: the same or different from research with adults?
}

\author{
Samantha Punch \\ Department of Applied Social Science, \\ University of Stirling, \\ Stirling \\ FK9 4LA \\ $U K$
}

Tel: 00.44.1786.467985

Fax: 00.44.1786.467689

Email: s.v.punch@stir.ac.uk 


\title{
Research with children: the same or different from research with adults?
}

\begin{abstract}
This paper explores seven methodological issues in some detail to illustrate the ways in which aspects of the research process usually considered to be the same for both adults and children can pose particular dilemmas for adult researchers working with children. It argues that research with children is potentially different from research with adults mainly because of adult perceptions of children and children's marginalised position in adult society but least often because children are inherently different. Drawing on classroom-based research carried out in rural Bolivia, the advantages and disadvantages of using five task-based methods (drawings, photographs, PRA techniques, diaries and worksheets) are highlighted in order to illustrate how such research techniques often thought to be suitable for use with children can be problematic as well as beneficial.
\end{abstract}

\section{Key words}

Children, Methodology, Task-based Methods, Visual Techniques, Written Methods

The way in which researchers perceive childhood and the status of children in society influences how children and childhood will be understood. This article explores the ways in which research with children is similar to or different from research with adults. Recently there has been much debate about this (for example Christensen and James 2000; Lewis and Lindsay 2000; Shaw 1996), and it has implications for the whole of the research process with children: design, methods, ethics, participation and analysis. It is somewhat paradoxical that within the new sociology of childhood many of those who call for the use of innovative or adapted research techniques with children, are also those who emphasise the competence of children. If children are competent social actors, why are special 'child-friendly' methods needed to communicate with them?

The paper begins with a discussion of why research with children is potentially different from research with adults. Seven methodological issues are explored in some 
detail to illustrate the ways in which aspects of the research process usually considered to be the same for both adults and children can pose particular dilemmas for adult researchers working with children ${ }^{1}$. The paper suggests that one way of researching a diversity of childhoods and taking into account children's varied social competencies and life experiences is to use a range of different methods and techniques. Subsequently, the discussion draws on examples of techniques used in classroom-based research carried out in rural Bolivia which explored children's everyday lives at home, at school, at work and at play (Punch 1998). The advantages and disadvantages of using five task-based methods (drawings, photographs, PRA techniques, diaries and worksheets) are highlighted in order to illustrate how such research techniques often thought to be suitable for use with children can be problematic as well as beneficial.

\section{Ways of seeing children affects ways of listening to children}

There has been a tendency to perceive research with children as one of two extremes: just the same or entirely different from adults. The way in which a researcher perceives the status of children influences the choice of methods. Those who consider children to be 'essentially indistinguishable from adults' (James et al. 1998: 31) employ the same methods as those used with adults, since children are seen as basically the same. It is then the responsibility of the adult researcher not to draw attention to any adult-child distinctions by treating them in any way other than as mature, competent people (Alderson 1995). However, such an approach may mean that the power imbalance between adult researchers and child subjects is not always adequately addressed (Morrow 1999). 
Those who perceive children as being very different from adults use ethnography as the most appropriate way to get close to understanding the child's world and the child's views are taken at face value (James et al. 1998). However, ethnography is not only suitable for those who perceive children as different. It is necessary to spend prolonged, or repeated, periods with anyone in order to get to know them beyond a one-off interview and to gain a greater understanding of their views and experiences (Fetterman 1989). The difficulty with using this approach is that it relies on participant observation as a research strategy often without recognising that adults are unable to be full participants in children's social worlds because they can never truly be children again (Fine and Sandstrom 1988; Hill 1997).

Recently James et al. have suggested that there is another perspective of those who perceive children to be similar to adults but to possess different competencies (1998: 189). Such researchers tend to use methods which are based on children's skills and this has led to a plethora of innovative or adapted techniques being developed, such as pictures and diaries (Nesbitt 2000), sentence completion and writing (Morrow 1999), drawings (Ennew and Morrow 1994; Swart 1990), the draw and write technique (Backett-Milburn and McKie 1999; France et al. 2000; Pridmore and Bendelow 1995) and radio workshops (Hecht 1998). However, such techniques should not unquestionably be assumed to be more appropriate for conducting research with children. Apart from being more suitable for children's competencies, other reasons for using them such as children's social location need to be considered (see also Harden et al. 2000). Furthermore, researchers should engage in a critical reflection of the use of such 'child-centred' methods in order to explore the advantages and disadvantages of how they work in practice and the implications for analysis of the different kinds of data 
that are generated. Reflexivity should be a central part of the research process with children where researchers critically reflect not only on their role and their assumptions (Davis 1998), but also on the choice of methods and their application.

Discussions about research with children have tended to focus on ethics especially the issues of informed consent and confidentiality (for example Alderson 1995; France et al. 2000; Lewis and Lindsay 2000; Morrow and Richards 1996; Stanley and Sieber 1992; Thomas and O’Kane 1998). Ethical issues are often thought to be the central difference between research with children and research with adults. For example, it is widely recognised that in order to gain children's consent and involvement in research, one has to go via adult gatekeepers who are able to limit researchers' access to the children. Whilst it is vital to recognise that children are potentially more vulnerable to unequal power relationships between adult researcher and child participant, ethics can dominate debates about methodological concerns. Many other research issues are often disregarded and not given further attention since they are considered to be the same as those with adults. These include developing rapport; not imposing the researcher's own views and interpretations; validity and reliability; bearing in mind the research context; and clarity of questions. Such dilemmas need to be considered when doing research either with adults or children, but are they exactly the same? Is there anything about research with children which makes it necessary to address these issues differently than with adults? Before examining what the potential differences are, the reasons why these issues are said to be different with children will be highlighted.

There are three broad areas of explanation: the position of childhood in adult society, adults' attitudes towards children and the children themselves. I shall consider each of these in turn. 
(a) Childhood as a social institution is constrained by adult society: Children are marginalised in adult-centred society. They experience unequal power relations with adults and much in their lives is controlled and limited by adults: "The main complications do not arise from children's inabilities or misperceptions, but from the positions ascribed to children” (Alderson and Goodey 1996: 106). Children are used to having much of their lives dominated by adults, they tend to expect adults' power over them and they are not used to being treated as equals by adults. As Mayall points out: "the concept of generation is key to understanding childhood. This means that the adult researcher who wishes to research with children must confront generational issues” (2000: 121).

(b) Adults perceive children to be different: Adults' fears, assumptions and attitudes affect their behaviour towards children. The researcher's own assumptions about the position of children in society affects the methods chosen as well as the interpretation of the data generated:

... while children as research subjects may be envisioned as sharing the status of adults, they are none the less thought to possess somewhat different competencies and abilities. It is up to researchers to engage with these more effectively. (James et al. 1998: 188)

Several researchers suggest that if children are not providing valid and reliable data, it is not the fault of the children but of the researcher for his/her 'adultist' attitudes towards them (Alderson 1995). Connolly suggests that 'the problem becomes one of being critically reflexive and forever questioning your role as a researcher and your relationships with those you have researched' (1998: 189). 
(c) Children are different from adults: There are some inherent differences about children which make them different from adults: they may have a limited and different use of vocabulary and understanding of words, relatively less experience of the world and may have a shorter attention span (Boyden and Ennew 1997). It is difficult to argue that research with a five year old is not at all different from research with a sixteen year old. Although developmental arguments may account for some of the distinctions between younger and older children, such arguments need to be used critically. In particular, it must be recognised that child development models are not universal but socially and culturally specific (Woodhead 1998).

\section{Is research with children different from adults?}

A variety of research issues will now be examined to see what makes them potentially different for research with children and which of the above three reasons provide the most appropriate explanations (see Table 1 for a summary).

Not imposing the researcher's own perceptions: A common concern for qualitative research with adults or children is not to impose the researcher's own views and to enable the research subjects to express their perceptions freely. The difference for research with children is that it is difficult for an adult researcher ever to totally understand the world from a child's point of view:

Assumptions that might seem valid because we believe that we know and understand children, both because we were children once and because we see them so often, present a methodological problem. (Fine and Sandstrom 1988: 35) 
As adults we were once children but we soon forget, unlearn and abandon elements of our childhood culture. Adults may have difficulty in 'obtaining the necessary distance to reflect on adult ways of conceptualizing children and childhood' (Solberg 1996: 53). This difference arises from adults' assumptions concerning what children are and what childhood is like (James et al. 1998; Thorne 1993: 12). Adults must strive to abandon the commonly held assumption that adults' knowledge is superior to that of children (Alderson and Goodey 1996).

Children are not used to expressing their views freely or being taken seriously by adults because of their position in adult dominated society. The challenge is how best to enable children to express their views to an adult researcher and how to 'maximise children's ability to express themselves at the point of data-gathering; enhancing their willingness to communicate and the richness of the findings' (Hill 1997: 180). In recent years, participatory methods, such as PAR (Participatory Action Research) and PRA (Participatory Rural Appraisal) techniques have been increasingly used for facilitating children's capacity to participate in research (for example Johnson et al. 1998; O’Kane 2000). These research methods not only provide opportunities for children to express themselves, but are also a potential source for empowering them for a fuller participation in society and for decision-making in matters which affect them (Boyden and Ennew 1997; Hart 1997; INTRAC 1997; PLA Notes 1996).

Validity and reliability: When eliciting children's views, another difficulty which child researchers must confront is that they are often asked if they can 'really believe' children's accounts of their experiences (Morrow 1999). A common assumption is that 
children lie or that they cannot distinguish between reality and fantasy. Children, like adults, may lie to researchers for several reasons: to avoid talking about a painful subject; to say what they think the researcher wants to hear; or through fear, shame or a desire to create favourable impressions (Ennew 1994; Gersch 1996; Richman 1993). It is recognised that: 'Lies and evasions are less likely when a researcher has built up a relationship of trust with children' (Ennew 1994: 57), but, as Ennew points out, the same can also be said for research with adults. Similarly, children's accounts have their own validity in terms of being their own perspectives and the way the world seems to them, even though, like any respondent, some of the 'facts' of their accounts may be wrong. The difference is that children are potentially more vulnerable to the unequal power relationship between child subjects and adult researchers (Alderson and Goodey 1996; Boyden and Ennew 1997; Hood et al. 1996; Mauthner 1997). The nature of childhood in adult society means that children are used to having to try to please adults, and they may fear adults' reactions to what they say. Time needs to be invested to form a relationship and gain their trust.

Clarity of language: In any research with adults or children, when forming research tools and questions, clarity of language is vital. However, adult researchers tend to be more conscious of their use of language in research with children. This stems from adult perceptions of children as non-competent (Mahon et al. 1996), or as having 'limitations of language and lack of articulateness' (Ireland and Holloway 1996: 156). Younger children may have a more limited vocabulary, but equally they may use different language which adults do not understand. Thus the language dilemma is mutual. Methods can be broadly adapted for older or younger age groups. For example, in my Bolivian study complex worksheets were more suitable for older children who had a 
higher level of literacy. Younger children tended to prefer drawing and were less inhibited by a lack of artistic competence.

Research context and setting: It is assumed to be as important to bear in mind the context and setting of the research for children as it is for adults. However, it needs to be recognised that many research environments are adult spaces where children have less control. Adult spaces dominate in society, thus it can be difficult to find child spaces in which to conduct research. For example, the school environment is a place for children to learn but is organised and controlled by adult teachers. Research conducted at school should take into account that children may feel pressure to give 'correct' answers to research questions. Adult researchers need to reassure children that there are no right and wrong answers. Participant observation with children in their own spaces can enable them to feel more comfortable. Yet adults should not assume that children necessarily prefer their own environment, they may actually prefer an adult researcher not to invade their child space. An awareness and sensitivity of the implications of the research setting needs to be considered with particular care in research with children.

Building rapport: It is commonly assumed that the need to build rapport with research subjects is the same for adults and children, but adults themselves may lack experience of building rapport with children. The underlying reason why it is potentially different with child research stems from adult fears of being patronising, not behaving appropriately and not finding common ground where rapport can be developed (see also Harden et al. 2000). An effective strategy is to react to the children and follow their guidelines (Cosaro 1997; Punch Forthcoming 2001). However, ultimately it depends on the skills of the adult researcher to develop rapport and build 
up a relationship of trust (see also Butler and Williamson 1994). It is also worth remembering that the researcher needs to be able to build rapport not only with children but also with the adult gatekeepers, such as parents or teachers (see also Morrow 1999).

Analysis: An additional issue of research with children is that the choice of which data to include and the interpretation of the data is in the power of the adult researcher. Particular care must be taken when interpreting children's views, because as Mayall points out, ultimately adult researchers analyse children's perspectives:

However much one may involve children in considering data, the presentation of it is likely to require analyses and interpretations, at least for some purposes, which do demand different knowledge than that generally available to children, in order to explicate children's social status and structural positioning. (Mayall 1994: 11)

Yet this can also apply to research with adults because "If academic research is to produce anything more than lay understandings it must involve access to concepts, theories and scholarly knowledge unavailable to most research subjects” (Harden et al. 2000: 6). However, the difference with children is the added danger that: 'As "grownups," we are limited by our tendency to process their talk through our own view of the world' (Fine and Sandstrom 1988: 9).

Using appropriate research methods: The issue of using appropriate methods is a central concern in any research but with children there seems to be a greater desire to develop fun, 'child-friendly' methods, drawing on familiar sources or children's particular interests. There are several reasons for this. First, adults assume that children prefer fun methods, and are more competent at them, and that children have a shorter 
attention span. Secondly, the nature of childhood in adult society means that children tend to lack experience of adults treating them as equals. They may also lack confidence at communicating directly with unfamiliar adults especially in a one-to-one situation. Thirdly, it may be that younger children do have a more limited concentration span. Also, since many children spend at least some time at school, they may be more used to visual and written techniques and may have different competencies (James et al. 1998: 188). However, adults should not assume that this is necessarily the case for all children.

Using methods which are more sensitive to children's particular competencies or interests can enable children to feel more at ease with an adult researcher. This does not mean that children are incapable of engaging with the methods used in research with adults:

The 'problem' of adult authority in relation to children may be more acute when the child and the researcher are together on a one-to-one basis. The adoption of more varied and imaginative research methods may make it possible to overcome these problems to some extent; for example ... interactive research methods such as video and drawings. (Mahon et al. 1996: 149)

The methodological issues which have been discussed are all relevant to research with adults and children. However, these issues are potentially different or particularly pertinent to the way research is conducted with children for a combination of reasons. Children, particularly younger children, may have different characteristics from adults. For example, their use of language and their understanding of the world may differ from adults. However, most often the reasons are a result of adults' perceptions and treatment 
of children in adult society and because of children's structural positioning and least often because children are inherently different (see Table 1).

\section{Reflections on using task-based methods with children}

From my experience, an effective way of carrying out research with children is to combine traditional research methods used with adults, and techniques considered to be more suitable for use with children (see also Punch Forthcoming 2001). By using traditional 'adult' research methods, such as participant observation and interviews, children can be treated in the same way as adults and display their competencies. Thus, they are not being patronised by using only special 'child-friendly' techniques. However, since children tend to lack experience of communicating directly with unfamiliar adults in a one-to-one situation, a more innovative approach such as using task-based methods can enable children to feel more comfortable with an adult researcher.

The problem with using innovative techniques is that the benefits and drawbacks of using them are not always scrutinised. A reflexive and critical approach is needed in order to recognise their disadvantages and limits, as well as the reasons for using them. For example, are certain methods being used with children purely because they are fun or because they also generate useful and relevant data? The implications of using different methods with children have begun to be examined only recently (BackettMilburn and McKie 1999; Christensen and James 2000; Hill 1997; Morrow 1999). Therefore, the aim of the final section of this paper is to contribute to the growing sociological literature on research methods with children by exploring some of the 
advantages and disadvantages of using a variety of different task-based methods to involve children in research.

The discussion draws on a recent experience of using drawings, photographs, diaries, PRA techniques (spider diagrams and activity tables) and worksheets with children in a rural community in Bolivia. This school-based research was carried out with 37 rural children, girls and boys aged 8-14. The aim of the study was to consider how children negotiate their independence as they grow up in rural Bolivia. The ethnographic methods of semi-participant observation and informal interviews were also used but are examined elsewhere along with a discussion of negotiating access and building relationships in the field (Punch 2001). The task-based methods were all conducted in the community school except for the photographs and diaries which were discussed at school but largely carried out by the children at home.

\section{Drawings $^{2}$}

I began the classroom-based research by asking the children to draw pictures which included spontaneous drawings on topics of the children's own choice, and two thematic drawings: My life in the community and My house and family. The advantage of using drawing with children is that it can be creative, fun and can encourage children to be more actively involved in the research. The use of drawing gives children time to think about what they wish to portray. The image can be changed and added to, which gives children more control over their form of expression, unlike an interview situation where responses tend to be quicker and more immediate (see Shaver et al. 1993). In this research, drawings were used in an exploratory manner to discover what children consider as important aspects in their lives, in order to avoid imposing adult-centred 
concerns (Sapkota and Sharma 1996). In addition, drawings were an appropriate warmup to more difficult activities, as well as being effective as an initial task to enable the children to become more familiar with the adult researcher (Boyden and Ennew 1997). They were also used as a useful fill-in activity, while waiting for other children to finish tasks. Finally, the drawings themselves are rich visual illustrations which directly show how children see their world.

However, it should not be assumed that drawings are a simple, 'natural' method to use with children as it depends on children's actual and perceived ability to draw. Some children, particularly older children, are more inhibited by a lack of artistic competence, and may not consider drawing to be a fun method. In Bolivia, children's perceived lack of ability is closely related to their lack of drawing practice. Also, since they live in a relatively isolated, rural community with no electricity, most of the children have had no contact with television, comics, magazines and other common visual images associated with the mass media. Such lack of contact with visual imagery influences the type and limited range of visual images that children produce (Bradley 1995). They tended to reproduce set images, learnt from the blackboard or their text books, and they were not used to forming very imaginative, exploratory images. The stylised images which they tended to draw included houses, flowers, trees, the school flag, animals (especially ducks), the river and crops which are: '... stereotyped images that relate to what they have learned to draw, which in turn is often an expression of a limited range of objects emphasized by the particular culture’ (Hart 1997: 162).

Another issue to be born in mind particularly during the analysis stage was whether the children had copied from friends or from text books (see also Swart 1990). The 
proximity of the desks meant that peer work could easily be seen and copied. I felt that this was not necessarily problematic as the drawings still represented children's ideas as a group, but it was important not to over-interpret the significance of certain recurring images. Consequently it was useful to look at the text books and exercise books which the children used at school to see what type of images they were familiar with and to what extent these were reproduced in their own drawings.

A difficulty which had not been anticipated was conflict over who used the felt-tip pens rather than the coloured pencils which I had bought for the research tasks. Pens were considered as 'superior' by the children since they are more expensive and usually only older children are 'allowed' to use them. With hindsight I should have provided pens for all the children to try and equalise access to them and to all the colours available (see also Shaver et al. 1993). Most of the children reacted enthusiastically to having blank paper to draw on, largely because the only medium available was faintly printed squared pages in their exercise books.

Using drawings as a class-based activity meant that it proved difficult to obtain all the children's interpretations of their individual drawings. Also, since their drawings were self-explanatory and representative, it was even felt to be insulting to ask the children what they had drawn, when it was quite clear that they had drawn a tree, a flower, or a house. The children may have felt that such questions only reinforced their selfperception that they could not draw. Care had to be taken not to misinterpret the children's drawings and impose adult interpretations in analysis. It proved difficult to distinguish cows from horses, sheep from dogs, and a house could be home or the school. Fortunately, most of the confusion was about the detail of the type of image, 
such as which kind of animal had been portrayed, and in the analysis all types of animals were categorised together under the heading 'animal', so the risk of misinterpretation was minimal. However, if I used the technique again I would systematically try to ask all the children in an open way to explain what their drawing meant to them and why they decided to draw those images (rather than ask them "what have you drawn”).

\section{Photographs}

I used photography as a visual method with seventeen of the school children who were from the class where I was given most opportunities to conduct the research activities (see Punch 2001). I showed them how to use a camera, including the basics of how it works and a selection of different photographic styles such as portraits, landscapes, close-ups and long-distance shots. They each took six photographs showing important aspects of their lives. Once the photos had been developed, the children wrote a brief paragraph about each of their photos describing what it showed and why they decided to capture that image.

The main benefit of using the photographic method was that the children enjoyed taking the photographs and learning how to use a camera; most of them had never held one before. It was something novel and different for them to do, so was a fun way for them to express themselves. The photographic technique did not depend on the children's ability, or their perceived ability, to depict an image. Most of the children quickly learnt how to take a picture, and an average of four out of their six photographs came out how they intended. Since action was more difficult to draw than things, photographs offered a reasonable alternative to drawings as children were freer to 
choose images to depict. By taking photographs children were less likely to copy their friends or text book images directly, but they may have copied the kind of things they have seen adults taking photos of, or may have taken the same sorts of pictures as their friends. A solution was to allow each child to take the camera home overnight and encourage them to take photographs of their own choice. An additional benefit of this was that the children took photographs of daily scenes at home which I had not observed directly.

One disadvantage of using such a visual technique is that the chosen image is influenced by the season when the photograph is taken. For example, several children took pictures of potato fields since it happened to be the time of year when the crop was in flower and looked its prettiest. Spontaneous images of an event occurring at that moment were more likely to be captured than depicted in a drawing. This may have led to an over-emphasis of importance for that event. For example, a photograph taken of boys fighting in the village square shows a particular moment in time, but does not necessarily mean that fighting is a very important aspect of their lives. Also, the children might have been more tempted to take pictures of what they wanted to keep as a photograph afterwards. Alternatively they may have taken pictures of what they considered makes a 'good' photograph. Such issues were important to bear in mind during the analysis stage, and highlight the importance of children describing their own reasons for taking the photographs.

There was a particular ethical problem of employing the visual photographic technique with children who usually do not have an opportunity to take photographs, since it briefly introduced them to a modern technology which they will be unlikely to 
experience again because of the financial cost involved. It may have left some children feeling disappointed afterwards at being unable to practise their newly learnt skill. It also caused some resentment from other community members for encouraging children to use such an expensive technique, and instilling unrealistic ideas into their heads about wanting to be photographers.

\section{PRA Techniques}

Two different kinds of techniques used in the research were adapted from PRA (Participatory Rural Appraisal): spider diagrams and activity tables. The spider diagram was titled 'Places that I know', and on each of the spider's legs the children wrote a place that they had been to, either outside or within their community. At the end of the spider's leg they indicated how many times they had been to that particular place and if they had been more than ten times they put a star to indicate many occasions. The aim of this exercise was to discover the extent of children's mobility and physical movement within and outside their community. The aim of the activity tables was to discover the range of activities and work that children do (see Punch Forthcoming 2002). They filled in a list of all the agricultural, animal-related and domestic tasks that they knew how to do, indicating whether they enjoyed doing that particular activity or not, and whether the activity was seasonal or year-round.

The advantage of using PRA techniques was that they were ideal for allowing children to define the relevant elements of the issue which was very useful for an initial research stage. Broad questions or themes were presented to them and they identified the key aspects. Subsequently, this was used to refine further questions to explore the issue in more detail on the worksheets. These tools started simply, and further information was 
added in stages to the diagram or table, increasing the depth of the data obtained. Such techniques actively involved children in a creative fun way, maintaining their interest as well as producing a wealth of information relatively rapidly. The disadvantage of using PRA techniques was that further methods needed to be used to discuss the issues raised in more detail. In this study, I do not claim that by using PRA techniques children were participating fully in the research process but that they were encouraged to express their views freely. The aim of using more participatory techniques was to listen to children's voices, enabling them to communicate their opinions. However, it is recognised that their participation was limited to active involvement in data generation rather than empowerment. French and Swain (1997) drew a useful distinction between 'emancipatory' research in which participants have control throughout the research process, and 'participatory' research in which they are actively involved in data generation, as in this study.

\section{Diaries}

One of the classroom-based activities consisted of showing the children how to write a diary of their lives, recording what they had done on the previous day, from when they got up to when they went to bed. Some children also chose to illustrate their account. I did not expect the children to want to continue writing these diaries as many of them wrote slowly and were not familiar with such a task. I was therefore surprised when all the children said that they would like to continue writing diaries at home. As time went on some children wrote less and less, but over half continued for more than two months. 
The diaries provided information about the everyday, routine aspects of children's lives. They showed a range of different activities which went beyond stereotypical notions that girls merely help their mothers while boys only help their fathers. The diaries allowed for a relatively easy comparison of the different sorts of activities that different children did on a daily basis. I could compare the accounts of girls' and boys', older and younger children, and children from different household compositions. The diaries were also useful in reflecting how children's activities varied greatly according to whether it was a school day or a weekend. Most of the children seemed to enjoy creating a document of their daily lives which they would be able to keep.

One of the difficulties with using the diary method was that it depended on the children's level of literacy. Initially the children spent a long time writing their first day's account, but several commented later that they had become much quicker at writing their diaries. They were children's personal accounts of what they had done, which tended to be summarised and omitted much detail. They tended to write only about the main activities, not mentioning when they did several activities simultaneously, or when they combined work with play. The season also affected the activities they described. The children's teacher encouraged them to continue writing their diaries by not setting them any other homework. This caused tensions with some parents who resented that the children spent time every evening writing their diary, often using it as an excuse not to help prepare dinner or bring the animals in.

\section{Worksheets}

I devised eight different worksheets for the children to complete during classtime which covered a variety of different aspects of their lives: 
(1) Their lives in the community: what they like and dislike doing

(2) Places where they go in the community, what and where they play

(3) Places they know and their mobility outside the community

(4) School: why they like/dislike school, what they learn, why they are absent

(5) Future: their aspirations and plans

(6) Argentina and migration: what they know and think about it

(7) Family relationships

(8) Work and the household division of labour

Some of these issues were closely related to issues explored in the other task-based methods. For example, questions in worksheet (1) on aspects of children's lives in the community, complemented the drawings and photographs they had done. Worksheets (2) and (3) were drawn up based on the spider diagrams. All the places that children had mentioned were put into a table to obtain more detailed information about why children went to those places and with whom they went. Worksheet (8) was drawn up as a result of the activity table which children had completed. All the activities that they had mentioned were listed and further columns were included so that children could state who usually did that activity in their household, who helped, who never did it and at what age they learnt or could learn to do it.

The worksheets allowed for more detailed information to be obtained on the issues identified by children as important in their lives. The first worksheets were simple, open questions of just one sheet. As children became more accustomed to working with me, and more used to my style of open questioning, they were able to fill in longer worksheets which explored more complex issues, using both open and closed questions. Parents and teachers were asked the same questions in semi-structured interviews as the 
children had answered on their worksheets. Thus children's responses could be compared to adults' responses, as well as comparing the differences between children.

I was fortunate that teachers were willing to allow me the time to work with their pupils because it was important that I was present while they filled in the worksheets to give the children an opportunity to ask questions. Sometimes, when there were up to twenty children completing them, it was difficult to be able to answer all their questions individually. This technique also depended on a reasonable level of literacy, so simpler, shorter versions of some of the worksheets were given to the younger children (8-10 years).

\section{Combining visual, written and traditional methods}

One of the main advantages of using visual and written methods is that it may lessen the problems of an unequal power relationship between the adult researcher and the child participant, where the child may feel under pressure to respond relatively quickly in the 'correct' manner. With the task-based methods, the interaction is between the children and the paper, or the children and the camera, which allows for familiarity with the researcher to be built up over time. Another benefit of using task-based research activities is that many children can complete them simultaneously, obtaining information more quickly and for a greater number of children than by using individual interviews or observation techniques (Boyden and Ennew 1997: 107). The visual and written methods were received favourably by most of the children, especially because they offered them a different and interesting alternative to their usual school-work. They became actively involved in the different tasks, rather than passively responding. 
They did not find themselves to be in an uncomfortable interview setting but used methods that could easily be accommodated in their familiar school surroundings.

The difficulties of using visual and written methods, especially in a class group with many children, is that much data is generated at the same time, meaning that it is difficult to discuss all the issues raised in further detail. Where possible children's descriptions and interpretations were sought for each drawing, photograph, and diagram, whether in written or verbal form, but this was not always feasible. Also, there are likely to be some differences between what children say they do and what they actually do in practice which is why it was necessary to include observation methods, rather than relying solely on task-based activities (see Punch 2001).

Innovative methods can be more interesting and fun (for the children and the researcher). However, they should be referred to as 'research-friendly' or 'personfriendly' techniques, rather than the patronising term 'child-friendly'. Many adults might also benefit from them and find them more appealing than traditional methods. Many of the techniques considered to be 'child-friendly' have been adapted from PRA methods originally used with adults. They are 'research participant-centred' rather than 'childcentred'. The challenge is to strike a balance between not patronising children and recognising their competencies, whilst maintaining their enjoyment of being involved with the research and facilitating their ability to communicate their view of the world.

A combination of techniques can enable the data-generation process to be fun and interesting for the participants as well as effective in generating useful and relevant data. For example, in the Bolivian study the children did not like filling in the 
worksheets quite as much as they enjoyed taking their own photographs. However, the data from the worksheets was more in-depth than that from the photographs, which was interesting but limited. Whilst children's preferences for different methods were taken into account, it was also recognised that there were limits to fulfilling all of their preferences as different children prefer different techniques. Some children prefer to draw, others to write or talk. As preferences and competencies vary from child to child in the same way as they do from adult to adult, it is impossible to find the ideal methods for research with children.

Using a range of methods, both traditional and innovative, can help strike a balance and address some of the ethical and methodological issues of research with children. Like other child researchers I found that using a variety of techniques was valuable: to prevent boredom and sustain interest (Hill 1997); to prevent biases arising from overreliance on one method (Ennew and Morrow 1994: 70; Morrow and Richards 1996: 101); to triangulate and cross-check data (INTRAC 1997; Lucchini 1996; Morrow 1999); to evaluate the usefulness of different methods (Hazel 1996; Morrow 1999) and to strike a balance between traditional and innovative methods.

Finally, it is worth mentioning that by comparing research with children to that with adults, there is a danger of bracketing all children together as a group in opposition to adults, and overlooking diversity amongst children. It should be recognised that not all the research issues mentioned in this paper will be problematic with all children as a plurality of childhoods exist (Qvortrup 1994). It should also be acknowledged that it is misleading to talk about 'child' and 'adult' research methods, since the suitability of particular methods depends as much on the research context as on the research subjects' 
stage in the life course. The choice of methods not only depends on the age, competence, experience, preference and social status of the research subjects but also on the cultural environment and the physical setting, as well as the research questions and the competencies of the researcher. A fundamental aspect of human-centred research is to respect individuality and take account of major group differences whether they be class, age, gender, disability, ethnicity or culture.

Therefore, I would argue that it is too simplistic to consider research with children as one of two extremes: either the same or different from adults. Instead it should be seen as on a continuum where the way that research with children is perceived moves back and forth along the continuum according to a variety of factors: individual children, the questions asked, the research context, whether they are younger or older children and the researcher's own attitudes and behaviour. Researchers need to be reflexive throughout the research process and critically aware of the range of reasons why research with children may be potentially different from research with adults. Perceiving children as competent social actors does not necessarily mean that research should be conducted in the same way as with adults. This is because many of the reasons underlying potential differences stem from children's marginalised position in adult society or from our own adult perceptions of children rather than being a reflection of children's competencies. 


\section{References}

Alderson, P. (1995) Listening to Children: Children, Ethics and Social Research. Ilford: Barnardo's.

Alderson, P. (2000) 'Children as Researchers: The Effects of Participation Rights on Research Methodology' in P. Christensen and A. James (eds) Research with Children: Perspectives and Practices, pp.241-75. London: Falmer Press.

Alderson, P. and C. Goodey (1996) 'Research with Disabled Children: How Useful is Child-centred Ethics?' Children \& Society 10: 106-116.

Backett-Milburn, K. and L. McKie (1999) 'A Critical Appraisal of the Draw and Write Technique', Health Education Research 14: 387-98.

Boyden, J. and J. Ennew (1997) (eds) Children in Focus: A Manual for Experiential Learning in Participatory Research with Children. Stockholm: Rädda Barnen.

Bradley, S. (1995) How People Use Pictures: An Annotated Bibliography. London: International Institute for Environment and Development.

Butler, I. and H. Williamson (1994) Children Speak: Children, Trauma and Social Work. London: Longman.

Christensen, P. and A. James (eds) (2000) Research with Children: Perspectives and Practices. London: Falmer Press.

Connolly, P. (1998) Racism, Gender Identities and Young Children: Social Relations in a Multi-ethnic, Inner-city Primary School. London: Routledge.

Cosaro, W. (1997) The Sociology of Childhood. London: Pine Forge Press.

Davis, J. (1998) 'Understanding the meanings of children: A reflexive process', Children \& Society 12 (5): 336-348. 
Ennew, J. (1994) Street and Working Children: A Guide to Planning. Development Manual 4, London: Save the Children.

Ennew, J. and V. Morrow (1994) 'Out of the Mouths of Babes', in E. Verhellen and F. Spiesschaert (eds) Children's Rights: Monitoring Issues, pp. 61-84. Gent: Mys \& Breesch.

Fetterman, D. (1989) Ethnography: Step by Step. Applied Social Research Methods Series Volume 17, London: Sage.

Fine, G.A. and K.L. Sandstrom (1988) Knowing Children: Participant Observation with Minors. Qualitative Research Methods. Series 15. London: Sage.

France, A., G. Bendelow and S. Williams (2000) ‘A 'Risky’ Business: Researching the Health Beliefs of Children and Young People' in A. Lewis and G. Lindsay (eds) Researching Children’s Perspectives, pp. 150-62. Buckingham: Open University Press.

French, S. and J. Swain (1997) 'Changing Disability Research: Participating and Emancipatory Research with Disabled People', Physiotheraphy 83 (1): 26-32.

Gersch, I. (1996) 'Listening to Children in Educational Contexts', in R. Davie, G. Upton and V. Varma (eds) The Voice of the Child: A Handbook for Professionals, pp. 27-48. London: Falmer Press.

Hammersley, M. and P. Atkinson (1995) Ethnography: Principles in Practice. London: Routledge.

Harden, J., S. Scott, K. Backett-Milburn and S. Jackson (2000) 'Can't Talk, Won’t Talk?: Methodological Issues in Researching Children’ Sociological Research Online, 5 (2) <http://www.socresonline.org.uk/5/2/harden.html>

Hart, R. (1997) Children's Participation: The Theory and Practice of Involving Young Citizens in Community Development and Environmental Care. Earthscan Publications Ltd: London. 
Hazel, N. (1996) 'Elicitation Techniques with Young People', Social Research Update 12, Guildford: University of Surrey.

Hecht, T. (1998) At Home in the Street: Street Children of Northeast Brazil. Cambridge: Cambridge University Press.

Hill, M. (1997) 'Participatory research with children'. Research Review. Child and Family Social Work, 2: 171-183.

Hood, S., P. Kelley and B. Mayall (1996) 'Children as Research Subjects: a Risky Enterprise', Children \& Society 10: 117-128.

INTRAC (1997) Involving Children in Research For Planning, Programming and Monitoring: A Pilot INTRAC Training Course. Oxford: INTRAC.

Ireland, L. and I. Holloway (1996) 'Qualitative Health Research with Children', Children \& Society 10: 155-164.

James, A., C. Jenks and A. Prout (1998) Theorizing Childhood. Cambridge: Polity Press.

Johnson, V., E. Ivan-Smith, G. Gordon, P. Pridmore and P. Scott (eds) (1998)

Stepping Forward: Children and Young People's Participation in the Development Process. London: Intermediate Technology Publications.

Kirby, P. (1999) Involving Young Researchers: How to Enable Young People to Design and Conduct Research. York: Joseph Rowntree Foundation.

Lewis, A. and G. Lindsay (eds) (2000) Researching Children's Perspectives.

Buckingham: Open University Press.

Lucchini, R. (1996) 'Theory, Method and Triangulation in the Study of Street Children’, Childhood 3: 167-170. 
Mahon, A., C. Glendinning, K. Clarke and G. Craig (1996) 'Researching Children: Methods and Ethics, Children \& Society 10 (2): 145-154.

Mandell, N (1991) 'The Least Adult Role in Studying Children’ in F. Waksler (ed.) Studying the Social Worlds of Children: Sociological Readings. London: The Falmer Press.

Mauthner, M. (1997) 'Methodological Aspects of Collecting Data from Children: Lessons from three Research Projects’, Children \& Society 11: 16-28.

Mayall, B. (1994) 'Introduction', in B. Mayall (ed.), Children's Childhoods: Observed and Experienced. London: The Falmer Press.

Mayall, B. (2000) 'Conversations with Children: Working with Generational Issues' in P. Christensen and A. James (eds) Research with Children: Perspectives and Practices, pp. 120-35. London: Falmer Press.

Morrow, V. (1999) '"It's cool, ... 'cos you can't give us detentions and things, can you?!": Reflections on Researching Children', in P. Milner and B. Carolin (eds) Time to Listen to Children, pp. 203-15. Routledge: London.

Morrow, V. and M. Richards (1996) 'The Ethics of Social Research with Children: An Overview', Children \& Society 10: 90-105.

Nesbitt, E. (2000) 'Researching 8 to 13 year-olds' perspectives on their experience of religion’ in A. Lewis and G. Lindsay (eds) Researching Children's Perspectives, pp. 135-49. Buckingham: Open University Press.

O’Kane, C. (2000) 'The Development of Participatory Techniques: Facilitating Children's Views about Decisions which Affect Them', in P. Christensen and A. James (eds) Research with Children: Perspectives and Practices, pp. 136-159. London: Falmer Press. 
PLA Notes (1996) 'Special Issue: Children's Participation', PLA Notes Number 25. London: International Institute for Environment and Development.

Pridmore, P. and G. Bendelow (1995) 'Images of Health: Exploring Beliefs of Children using the "Draw-and-write Technique”, Health Education Journal 54: 473-88.

Punch, S. (1998) Negotiating Independence: Children and Young People Growing Up in Rural Bolivia. University of Leeds: Ph.D Thesis.

Punch, S. (2001) 'Multiple Methods and Research Relations with Children in Rural Bolivia', in M. Limb and C. Dwyer (eds) Qualitative Methodologies for Geographers, London: Arnold.

Punch, S. (Forthcoming 2001) 'Interviewing Strategies with Young People: The 'Secret Box’, Stimulus Material and Task-based Activities’, Children \& Society.

Punch, S. (Forthcoming 2002) 'Household Division of Labour: Generation, Gender, Age, Birth Order and Sibling Composition', Work, Employment \& Society.

Punch, S. and R. Baker (1997) Visual Representation: Using Drawings and Photographs as Research Methods with Children in Nepal and Bolivia, Paper presented at Urban Childhood conference in Trondheim, June 1997.

Qvortrup, J. (1994) 'Childhood Matters: An Introduction’, in J. Qvortrup, M. Bardy, G. Sgritta and H. Wintersberger (eds) Childhood Matters: Social Theory, Practice and Politics, pp. 1-23. Aldershot: Avebury.

Richman, N. (1993) Communicating with Children: Helping Children in Distress. Development Manual 2, London: Save the Children.

Sapkota, P. and J. Sharma (1996) 'Participatory Interactions with Children in Nepal', PLA Notes Number 25, London: International Institute for Environment and Development 
Shaver, T., V. Francis and L. Barnett (1993) Drawing as Dialogue: A qualitative approach to needs assessment for health education planning, ERG Technical Notes series No.2, Liverpool School of Tropical Medicine: Liverpool.

Shaw, I. (1996) 'Unbroken Voices: Children, Young People and Qualitative Methods' in I. Butler and I. Shaw (eds) A Case of Neglect? Children's Experiences and the Sociology of Childhood, pp. 19-36. Aldershot: Avebury.

Sinclair, R. (1996) 'Editorial’, Children \& Society, 10 (2):87-89.

Solberg, A. (1996) 'The Challenge in Child Research from 'being' to 'doing',' in J. Brannen and M. O'Brien (eds) Children in Families: Research and Policy, London: Falmer Press.

Stanley, B. and J. Sieber (1992) Social Research on Children and Adolescents:

Ethical Issues. London: Sage.

Swart, J. (1990) Malunde: The Street Children of Hillbrow. Witwatersrand University Press: Johannesburg

Thomas, N. and C. O'Kane (1998) 'The Ethics of Participatory Research with Children’, Children and Society 12: 336-348.

Thorne, B. (1993) Gender Play: Girls and Boys in School. Buckingham: Open University Press.

Woodhead, M. (1998) Children's Perspectives on their Working Lives: A Participatory Study in Bangladesh, Ethiopia, The Philippines, Guatemala, El Salvador and Nicaragua. Stockholm: Rädda Barnen.

\footnotetext{
${ }^{1}$ It has been suggested that a solution to the power imbalance between adult researcher and child participant is to involve children more directly as researchers themselves (Alderson 2000; Kirby 1999). Whilst this can resolve some issues, it can also create new dilemmas (Harden et al. 2000) and the aim of this paper is to focus on adults who conduct research with children.

${ }^{2}$ For this section on drawings grateful acknowledgment goes to Rachel Baker for her comments and contribution to a joint paper which we presented at the Urban Childhood conference in Trondheim, June
} 
1997: Visual Representation: Using Drawings and Photographs as Research Methods with Children in Nepal and Bolivia, (see Punch and Baker 1997). 